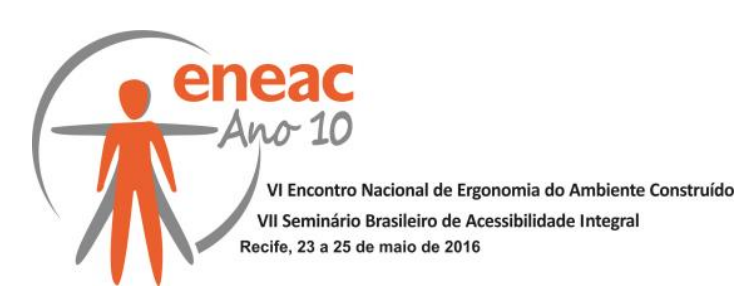

\title{
PROPOSTA PARA A AVALIAÇÃO DA QUALIDADE PERCEBIDA DE VITRINAS
}

\author{
SILVA JÚNIOR, José Adilson da (1); \\ COSTA FILHO, Lourival (2) \\ (1) Universidade Federal de Pernambuco | CAC | Mestrando em Design \\ e-mail: silvajunior.adilson@hotmail.com \\ (2) Universidade Federal de Pernambuco | CAA | Doutor em Desenvolvimento Urbano \\ e-mail: lourivalcosta@yahoo.com

\begin{abstract}
RESUMO
Este artigo objetiva apresentar proposta para a avaliação da qualidade visual de vitrinas a partir da percepção de especialistas e não especialistas no assunto. A Teoria das Facetas foi escolhida para a estruturação da investigação empírica, que elegeu o Sistema de Classificações Múltiplas como instrumento para coleta dos dados e o procedimento não métrico e multidimensional SSA (Smillarity Structure Analysis) para interpretá-los. Espera-se que as evidencias empíricas possam confirmar as hipóteses inicialmente propostas, revelar conceitos envolvidos e sua estrutura interna, a forma como eles se inter-relacionam no tipo de avaliação proposto, além do consenso entre os grupos amostrais.
\end{abstract}

Palavras-chave: vitrina; qualidade percebida; Teoria das Facetas.

\begin{abstract}
This article aims to present a proposal for the assessment of the visual quality of window displays as perceived by experts and non-experts. Facet Theory was chosen for the structure of the empirical research. A Multiple Sortings Procedure was selected as the tool to collect the data, and the nonmetric multidimensional procedure of SSA (Smillarity Structure Analysis) was used to interpret it. It is hoped that the empirical evidence will confirm the hypotheses which were initially proposed, and unearth the concepts involved, their internal structures, and the way they interrelate in this type of evaluation, as well as the consensus between the groups which were sampled.
\end{abstract}

Keywords: window displays; perceived quality; Facet Theory.

\section{INTRODUÇÃO}

Esta comunicação relata a estruturação teórica e empírica de uma pesquisa que está em andamento para o desenvolvimento de dissertação de mestrado em design. A pesquisa visa a identificação de categorias relacionadas com julgamentos perceptuais/cognitivos e julgamentos emocionais determinantes para a avaliação da qualidade visual de vitrinas de rua ou externas. Assim, as respostas avaliativas das pessoas para as características visuais de vitrinas serão priorizadas na abordagem, em detrimento do seu discurso publicitário.

A vitrina de rua ou externa, objeto de estudo empírico desta pesquisa, pode ser vista nas fachadas dos estabelecimentos comerciais pelos cidadãos/transeuntes que circulam a pé ou em veículos motorizados. Devido ao alcance e a incidência do objeto de estudo enfocado, de acordo com a visão de Bigal (2001), existe pouca probabilidade de as pessoas passarem diante de uma vitrina, em áreas centrais das cidades, sem lançar um olhar, seja esse diametral, diagonal, paralelo ou frontal. 


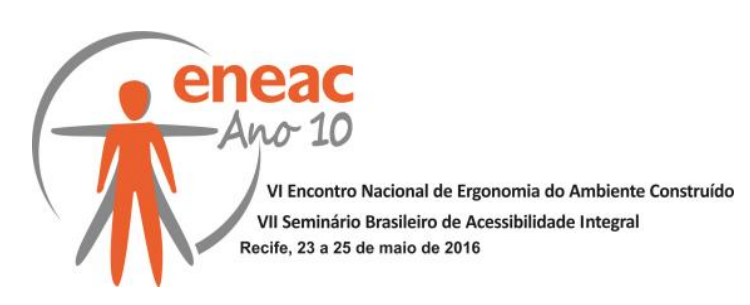

Com a proliferação dos centros comerciais e a concorrência acirrada do setor de comércio e serviços varejistas, a vitrina passou a ser engendrada de maneira sistemática e estrutural (WOLF, 2014) e, dentro desse contexto, orientações com base em dados empíricos sobre a qualidade visual de vitrinas são referências importantes para produzir o resultado desejável, já que as pessoas tendem a ser atraídas pelas vitrinas que mais Ihes agradam.

As características visuais dos ambientes têm impacto importante na experiência humana. Podem evocar fortes emoções como prazer ou desagrado, atuar como efeito estressor ou restaurador e possibilitar inferências sobre lugares e pessoas. Podem também influenciar o comportamento humano, como a decisão de ir ou de evitar certos lugares. E, como as pessoas respondem as inferências derivadas de estímulos visuais e não-visuais de lugares, a qualidade visual do entorno de um indivíduo tem efeitos poderosos sobre sua experiência (NASAR, 2000). Apesar das respostas avaliativas, por si só, não poderem prever o comportamento real, a avaliação combinada de respostas avaliativas e o comportamento previsto dá uma boa indicação do comportamento real (NASAR, 1988). Levando em conta essa afirmação, nesta pesquisa, os participantes serão solicitados a avaliar o grau que eles gostariam de visitar, comprar, ou permanecer diante de várias vitrinas.

Apesar de profissionais de projeto teorizarem sobre a qualidade visual urbana, as análises empíricas sobre a qualidade visual percebida de vitrinas têm ficado para trás. Somando-se a isso, de acordo com Bigal (2001), há uma enorme lacuna na literatura que versa sobre esse tema, cuja maior produção refere-se quase que exclusivamente ao modo de como organizar os elementos - diagramação, cores, materiais, produtos - no momento de conceber estudo para o projeto de design de vitrinas.

Exposta a problematização da pesquisa em andamento, admite-se ser relevante responder: 1| quais características da vitrina de rua são aderentes/determinantes para a avaliação de sua qualidade visual; 2| quais os efeitos emocionais que tais características desencadeiam; 3| o consenso desses resultados entre os diferentes grupos abordados.

Buscando responder essas questões, delineou-se como objetivo geral desta pesquisa avaliar a qualidade percebida de vitrines. Considerando-se vitrinas do comércio varejista do centro de Caruaru e dois diferentes grupos locais de especialistas e não especialistas no assunto, elencam-se, ainda, como objetivos específicos: 1| testar a aderência de certas características visuais de vitrinas para a avaliação da sua qualidade visual percebida; 2 | verificar a influência dessas características nos aspectos de prazer, excitação e calmaria em vitrinas; 3 | analisar o consenso dos resultados entre os dois diferentes grupos abordados.

Tais objetivos, relacionados com a avaliação subjetiva de lugares, têm se refletido no estudo do espaço pela arquitetura/urbanismo e ergonomia, que passaram a se interessar por duas noções relacionadas com o modo como os indivíduos percebem e tomam decisões a respeito do ambiente. O estudo dessas relações pode levar a uma melhor compreensão da vitrina, fornecendo subsídios projetuais para a melhoria da sua qualidade visual percebida.

Do ponto de vista teórico-metodológico, propôs-se uma investigação empírica estruturada através da Teoria das Facetas, que fara uso do Sistema de Classificações Múltiplas para coletar os dados e do procedimento não-métrico e multidimensional da SSA (Similarity Structure Analysis) para interpretá-los/analisá-los.

\section{QUESTÕES TEÓRICAS}

Esta seção trata de aspectos teóricos relacionados ao estudo das interações subjetivas que a vitrina pode desencadear no consumidor, numa abordagem híbrida que justifica, a partir das questões da pesquisa e dos objetivos estabelecidos, a consideração de construtos conceituais importantes para a avaliação da qualidade percebida de vitrinas. 


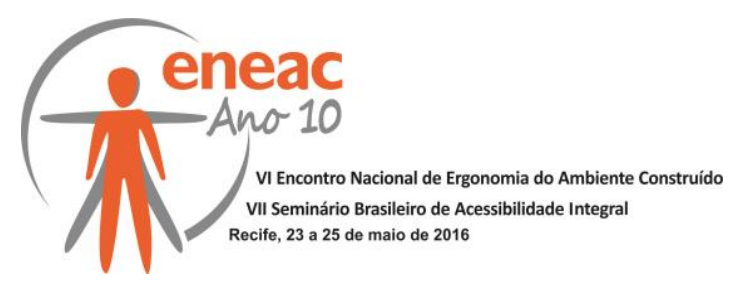

A maneira como o tema será abordado nesta seção, coloca o enfoque do objeto de estudo empírico antes do teórico. Desse modo, primeiro aborda-se a vitrina, enfatizando definições, características e funções. Em seguida, apresentam-se questões relacionadas com o tipo de avaliação subjetiva que se pretende realizar.

A pesquisa em andamento está delimitada à vitrina do tipo de rua ou externa que, de acordo com Lourenço e Sam (2011), é definida pelo espaço que separa a loja da calçada, podendo ser aberta (quando tem piso, teto e laterais, mas não apresenta fundo) ou fechada (quando tem piso, teto, laterais e fundo). Esse tipo de vitrina tem um inequívoco papel em qualquer estabelecimento comercial, pois opera como um espaço de contato imediato com o público.

As vitrinas são uma amostra do que a loja tem a oferecer. Devem estimular o interesse da compra, assim como reforçar a posição institucional da loja no mercado. As formas de exposição induzem à exploração de um determinado tipo de produto. Podem indicar a modernidade ou mesmo a sofisticação das mercadorias e dos serviços oferecidos pelas lojas. Essa forma de transmissão da imagem da loja é direcionada ao consumidor, que possui a sua própria percepção da mensagem (VARGAS, 2001).

Ao estimular o consumidor através dos sentidos e principalmente através da visão, a vitrine pode levá-lo a aceitar a oferta através da emoção e efetivar uma compra por impulso. Dessa forma, transforma-se em fonte geradora de estímulos perceptivos para quem a experiencia. Cada vitrina é entendida a partir das informações que se tem dela, desencadeando uma relação de interdependência entre vitrina e informação. A apreensão da vitrina ocorre por meio das formas de apropriação que se faz dela. Toda vitrine, portanto, é identificada por determinadas características que compõem sua particularidade. A síntese dessas relações não é um processo lógico, simples, resultado do conhecimento dessas mesmas relações.

A avaliação ambiental decorre da pessoa e do ambiente, além da continua interação entre os dois. Pode variar com a biologia, a personalidade, a experiência sociocultural, os níveis de adaptação, os objetivos, as expectativas e os fatores internos e externos. O observador interpreta e organiza tais estímulos como insumos para decidir sobre o produto e a loja (percepção ambiental). Pode também decorrer do significado da forma. Isso requer atividade mental para reconhecer o conteúdo formal, fazer inferências sobre tal e colocá-lo num quadro mental, e avaliá-lo (cognição ambiental). Em suma, filtram-se as respostas avaliativas através da lente da percepção e da cognição do ambiente (NASAR, 1998).

Diversos tipos de estratégias podem ser utilizados pelos vitrinistas na composição de vitrina, a fim de organizar os elementos visuais que compõem sua narrativa de apelo persuasivo. Entre outras, destaca-se a coerência entre as partes integrantes do todo compositivo, no sentido de evitar o distanciamento ou a descontinuação na ordem previamente estabelecida (OLIVEIRA,1997).

Qualquer ambiente, todavia, irá variar na probabilidade de evocar uma imagem de avaliação favorável entre vários observadores e culturas. Logo, por causa das experiências únicas e da singularidade de cada ser humano, a avaliação de uma vitrina varia entre observadores.

Reconhecendo possíveis diferenças individuais na resposta, Lynch (1997), em sua pesquisa seminal sobre a imagem da cidade, desenvolvida em 1960, destacou áreas de concordância substancial. Ele argumentou que a imagem de grupo, representada por um consenso entre número significativo de indivíduos, tem valor para as decisões projetuais de ambientes.

Dentro dessa perspectiva, os vitrinistas que planejam vitrinas para serem lidas/visualizadas por muitas pessoas precisam saber os prováveis efeitos dessas manipulações sobre elas. Por isso, a pesquisa em andamento busca ressaltar as respostas avaliativas compartilhadas por grande número de pessoas de diferentes grupos, numa investigação empírica.

Estudos identificam seis características ambientais relacionadas com a preferência: ordem, moderada complexidade, abertura, conservação, naturalidade e importância histórica. As 


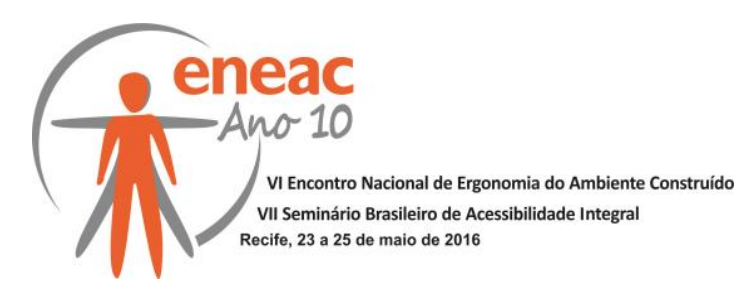

três primeiras - ordem, moderada complexidade, abertura - parecem representar variáveis formais, já as outras - conservação, naturalidade, importância histórica - parecem representar variáveis de conteúdo ou simbólicas. As pessoas podem gostar de várias dessas variáveis devido à sua contribuição para a coerência da cena (NASAR, 2000). Para Kaplan e Kaplan (1982), o ser humano tem predisposição para a coerência, porque favorece sua sobrevivência, pois o ambiente precisa fazer sentido para que se possa operar nele.

Duas características de vitrinas - complexidade e coerência - foram escolhidas para estudo, por causa de suas prováveis influências sobre a qualidade visual percebida. De acordo com Kaplan e Kaplan (1982), os seres humanos preferem ambientes que oferecem envolvimento e fazem sentido. A complexidade contribui para a preferência por envolver o observador, já a coerência por tornar o ambiente compreensível.

Por definição, a complexidade cria incerteza, que, por sua vez, provoca o envolvimento. Pouca complexidade é monótona e cansativa; muita é caótica e estressante. O nível médio de complexidade parece ser mais agradável, ou ideal. Assim sendo, o tom hedônico da cena (prazer ou beleza) tem sido postulado como tendo a forma de "U" invertido em relação à complexidade (BERLYNE, 1972; WOHLWILL, 1976).

Auxiliando a compreensão, a coerência deveria reduzir a incerteza e elevar o tom hedônico. A coerência - obtida pela redução do contraste dos elementos na cena - pode reduzir a incerteza e aumentar o tom hedônico (WOHLWILL, 1976; KAPLAN; KAPLAN, 1982).

A complexidade será manipulada, na pesquisa em andamento, pela alteração em três níveis de variação (pouca, média, muita) entre localização, forma e direção dos elementos de composição interna de várias vitrinas, enquanto a coerência, de modo semelhante, focará no contraste entre a cor e o tamanho dos mesmos elementos.

O tipo de avaliação que está sendo considerado na pesquisa em andamento - qualidade visual percebida - também se refere a emoções favoráveis e a significados experienciados em relação a vitrinas de rua. Apesar do prazer representar um componente importante de significado avaliativo, a imagem também tem outras dimensões. Usando uma variedade de estratégias de investigação e medidas, os psicólogos James Russel e Larry Ward encontrou quatro dimensões: prazeroso, estimulante, emocionante e relaxante (NASAR, 1998).

Em relação a essas respostas afetivas, o prazer é uma dimensão puramente avaliativa. A estimulação independe da dimensão avaliativa. A emoção e o relaxamento envolvem misturas de avaliação e estimulação. As pessoas experienciam lugares emocionantes como mais prazerosos e estimulantes do que os entediantes; experienciam lugares relaxantes como mais prazerosos, mas menos estimulantes do que os aflitivos (NASAR, 1998).

Igualmente importante para esta pesquisa é o enfoque da ergonomia. A ergonomia do ambiente construído vem se interessado em discutir as interações dos usuários com 0 ambiente, contemplando tanto a consideração de aspectos de ordem física quanto a identificação da percepção dos usuários. O enfoque ergonômico estabelece a necessidade de abordagem sistêmica (humano-atividade-ambiente) ampla e sob o prisma do usuário, vasto leque de variáveis que demandam esforços advindos de diversas áreas envolvidas no processo de projeto do espaço, tornando esse campo um dos mais completos para discutir as interações do ambiente sobre o ser humano.

Ao considerar o ser humano como elemento principal do sistema, é impossível planejar o estudo de um ambiente a partir da lógica ergonômica sem buscar compreender a percepção do usuário sobre tal, uma vez que o usuário é o componente que diretamente irá sofrer o impacto das possíveis sensações transmitidas por esse espaço (VILLAROUCO, 2011).

Ao abordar as condições necessárias para o projeto de ambientes, Bins Ely (2004) afirma a importância de conhecer os elementos do ambiente que podem causar estímulos sensoriais (perceber e receber informações) e provocar respostas ao nível do corpo, traduzidas no 


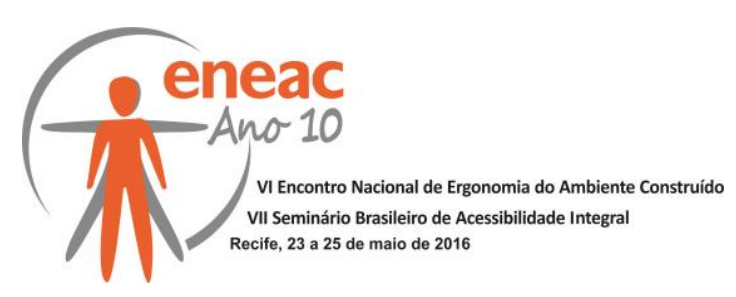

comportamento. Ainda segundo a autora, som, cor, aroma, textura e forma são alguns exemplos de elementos que podem provocar sensações e promover bem-estar emocional.

As interações do indivíduo com o ambiente a partir de suas sensações e percepções, interferem na sua forma de agir (MONT'ALVÃO; FIGUEIREDO, 2004). No caso, interferem na decisão de visitar, comprar ou permanecer diante de várias vitrinas, além de exercerem efeitos sobre outras variáveis comportamentais derivadas de suas qualidades percebidas como prazer/desgosto, estimulante/enfadonho, emocionante/frio, relaxante/perturbador.

A vitrina, sob esse ponto de vista, atende necessidades funcionais de informar e persuadir, bem como necessidades estéticas de seduzir as pessoas, podendo ser tomada como um ambiente construído, já que esse se trata, segundo Baptista et al (2002), de um espaço organizado, que constitui um meio físico e estético, informativo e psicológico especialmente projetado para agradar, servir, proteger e unir as pessoas no exercício de suas atividades.

A partir das chaves de leitura e dos ensinamentos compartilhados nas disciplinas cursadas no Programa de Pós-Graduação em design onde a dissertação está sendo desenvolvida, as preocupações e o posicionamento da ergonomia do ambiente construído se apresentam como oportunos nesta pesquisa, no sentido de contribuir nas discussões da percepção de vitrinas, priorizando o conhecimento das necessidades de seus observadores/consumidores, e na obtenção de dados que alicercem requisitos empíricos para a elaboração de projetos.

\section{QUESTÕES TEÓRICO-METODOLÓGICAS}

A pesquisa em andamento adota a Teoria das Facetas (TF) no desenho da investigação empírica, explorando os principais fundamentos dessa meta-teoria, uma teoria sobre como formular e testar teorias. O modo integrado de construção da investigação, a partir da TF, abrange a conceituação do objeto, o desenho dos instrumentos de pesquisa e análise dos dados (SHYE; ELIZUR; HOFFMAN, 1994; BILSKY, 2003).

A TF visa controlar a correspondência entre os níveis teórico e empírico de uma pesquisa e, inicialmente, envolve a identificação dos diferentes conceitos ou dimensões que delineiam a pesquisa, podendo advir da literatura ou de explorações in loco. Essa etapa consiste em estabelecer hipóteses, encontrar as facetas do modelo teórico e definir os elementos que as constituem. Cada faceta representa uma categoria conceitual, constituída por subcategorias de elementos a serem testados (COSTA FILHO, 2012). Assim, uma faceta considerando os tipos de vitrinas, por exemplo, teria subcategorias abrangendo o tipo fechado e o tipo aberto.

De forma resumida, de acordo com Bilsky (2003), diferenciam-se três tipos de facetas: o primeiro se refere à população de sujeitos da pesquisa (background). $O$ segundo abrange 0 conteúdo das variáveis pesquisadas (conteúdo). As facetas de população e conteúdo juntas determinam o campo de interesse da pesquisa (domínio). O terceiro tipo se refere ao universo das reações ou respostas dos sujeitos pesquisados (racional comum).

Há três facetas básicas de conteúdo para a avaliação ambiental, cada uma representa um componente do lugar investigado: referente, foco, nível. A faceta de referente expõe os diferentes aspectos que as pessoas se baseiam para realizar suas avaliações. A faceta de foco modula o referente da experiência. A faceta de nível leva em conta a existência da escala ambiental, que interfere na avaliação de uso dos espaços. Essas relações entre os diversos aspectos da experiência das pessoas com um determinado lugar podem ser sumarizadas através de uma sentença estruturadora, que descreve os componentes físicoespaciais e a forma como eles são experienciados (COSTA FILHO, 2014).

Depois de identificadas, todas as facetas devem ser relacionadas entre si para formar um quadro conectivo sob a forma de uma sentença estruturadora, que estabelece as relações entre todas as facetas através de seus diferentes elementos. 


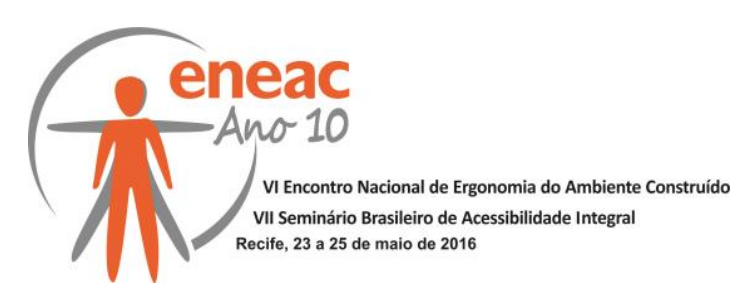

Cabe agora apresentar a aplicação da Teoria das Facetas nesta pesquisa. O Quadro 1 propõe a sentença estruturadora para a avaliação de vitrina, os nomes das facetas de conteúdo e seus elementos de composição interna. Essa sentença é uma expressão da qualidade visual percebida de vitrinas. O primeiro tipo de faceta se refere à população abordada (background). O segundo tipo abrange o conteúdo das variáveis pesquisadas e, juntamente com a faceta de background, define o domínio desta pesquisa. $O$ terceiro tipo descreve o universo de respostas possíveis (racional) em relação ao domínio da pesquisa.

\section{Quadro 1: Sentença Estruturadora de avaliação da qualidade visual de vitrina}

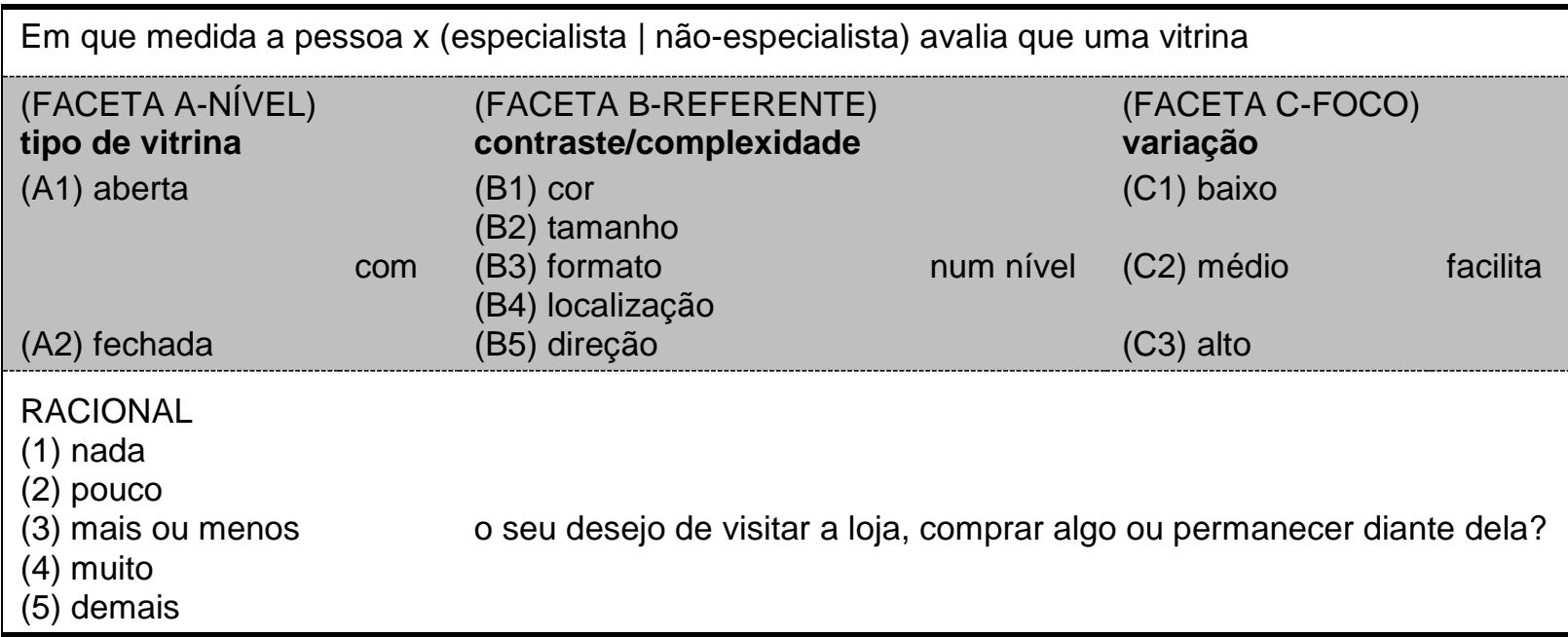

FONTE: Os autores baseados na pesquisa

A população que se pretende avaliar na pesquisa foi constituída por dois diferentes grupos de interesse no objeto de estudo empírico: 1| especialistas; 2| não especialistas.

As três facetas de conteúdo, relacionadas com a qualidade percebida de vitrinas - tipo de vitrina, contraste/complexidade dos displays, variação - foram consideradas hipoteticamente importantes para a avaliação pretendida. A faceta de nível da experiência $(A)$, responsável por determinar a escala do lugar, neste caso relaciona-se com os tipos de vitrina, que pode ser: aberta ou fechada. A faceta de referente da experiência (B) representa atributos ambientais que podem ser tomados para realizar as avaliações, diferenciados por atributos associados a redução do contraste e ao controle da complexidade nas cenas - cor, tamanho, formato, localização, direção - relacionados aos vários elementos de composição interna de vitrinas. A faceta de foco da experiência $(\mathrm{C})$, que modula o referente, representa a variação dos elementos nas cenas: baixa, média, alta.

As combinações dos elementos internos das três facetas de conteúdo (A2xB5xC3) totalizam 30 conjuntos de diferentes situações a serem avaliadas.

O racional, que descreve as possíveis respostas da população à qualidade percebida de vitrinas, tem 5 intervalos: 1| nada; 2| pouco; 3| mais ou menos; 4| muito; 5| demais.

A sentença estruturadora de avaliação da qualidade percebida de vitrina aqui proposta, como uma referência inicial da pesquisa, é analisada em relação aos resultados empíricos que devem confirmar ou refutar as hipóteses levantadas. Logo, após a análise/interpretação dos dados, há informações suficientes para construir ou não uma nova sentença, a ser estruturada como uma consequência direta dos resultados empíricos apurados. 


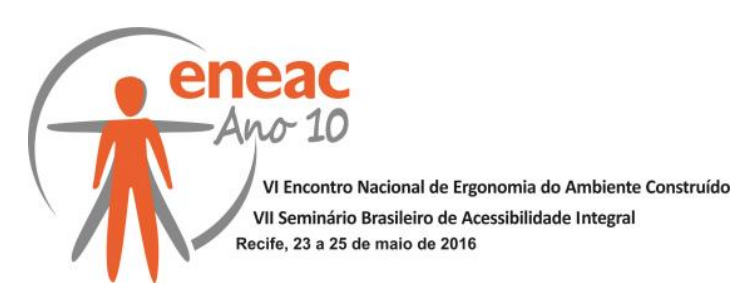

\section{QUESTÕES METODOLÓGICAS}

Nesta seção expõem-se as considerações metodológicas esboçadas para a investigação empírica. O desenvolvimento da metodologia, todavia, é parte integrante da pesquisa que está em andamento e precisa ser submetida a testes de consistência antes de ser tomada como definitiva.

Para a coleta dos dados, optou-se pelo Sistema de Classificações Múltiplas (CANTER; BROWN; GROAT, 1985), que consiste em solicitar informações aos participantes para classificar os mesmos elementos diversas vezes, com a finalidade de compreender suas ideias sobre o objeto de estudo.

O Sistema de Classificações Múltiplas vem sendo muito utilizado para explorar experiências ambientais (COSTA FILHO, 2014), e sua aplicabilidade foi ampliada por permitir o uso de ilustrações e outros materiais visuais difíceis de acomodar dentro de outros instrumentos.

A pesquisa adotará como elementos de estímulo, para serem classificados, um conjunto de fotografias de vitrinas de rua. A geração desse conjunto, contudo, precisa estar diretamente associada às variáveis desta pesquisa, todas listadas na sentença estruturadora para a avaliação da qualidade visual de vitrinas, que estabelece precisamente a relação entre todas as partes envolvidas, ou seja, a população amostral, o que se pretende avaliar, os referentes, o foco e o nível da experiência, bem como o racional comum às respostas.

Pretende-se utilizar, junto aos participantes, duas classificações "dirigidas". Nesse tipo de classificação, solicita-se que o entrevistado classifique os elementos conforme critérios preestabelecidos. Na primeira classificação, que busca responder ao primeiro objetivo específico da pesquisa, os respondentes serão convidados a indicarem o grau em que eles gostariam de visitar, comprar ou permanecer diante de várias vitrinas, e têm a finalidade de verificar a aderência de certas características da vitrina para a avaliação de sua qualidade visual percebida. Na segunda classificação, que se propõe a responder ao segundo objetivo específico proposto, os respondentes serão solicitados a indicar o grau em que percebem prazer/agradabilidade, emoção e tranquilidade em várias vitrinas de ruas.

As classificações realizadas serão registradas em um formulário especialmente elaborado. Como todos os participantes abordados serão submetidos aos mesmos procedimentos, os dados que variam limitam-se às informações específicas de cada grupo (especialistas - não especialistas), restritas à primeira página do modelo proposto.

Conforme apurado por Stamps (1992), quando se trata da avaliação da qualidade visual do ambiente, pode-se obter resultados muito confiáveis ao utilizar, como elementos de estímulo, fotografias coloridas, vídeos, slides, fotomontagens e simulações.

Os dados obtidos nas classificações dirigidas serão interpretados através do procedimento não-métrico e multidimensional da SSA (Smilarity Structure Analysis), executado com o auxílio do programa informático HUDAP (Hebrew University Data Analysis Package).

A SSA, de acordo com Roazzi, Monteiro e Rullo (2009), é um sistema de escalonamento multidimensional concebido para analisar a matriz de correlações entre " $n$ " variáveis representadas graficamente como pontos num espaço euclidiano. O sistema fundamenta-se no princípio da contiguidade que, como tal, traduz as relações de similaridades entre itens, configurado pelas distâncias entre os pontos. Isso significa que a proximidade das variáveis no espaço multidimensional é proporcional ao grau de correlação que apresentam. Essas relações de similaridades podem formar regiões de contiguidade que possibilitam verificar se as hipóteses iniciais são transformadas em hipóteses regionais, em relação às quais se espera evidenciar regiões que abarquem aos elementos internos de cada faceta.

A solução da SSA propriamente dita compreende um mapeamento de todos os itens processados para um espaço de dimensionalidade especificada. Na pesquisa, essa solução 


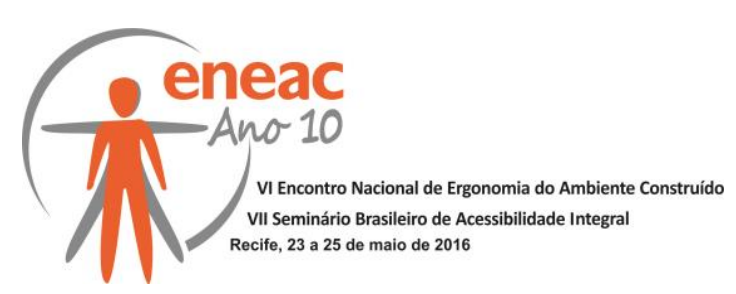

compreenderá o processamento das fotografias de vitrinas categorizadas por cada um dos participantes da amostra para um espaço bidimensional (diagrama do espaço da SSA).

As análises dos diagramas da SSA podem revelar relações e regras implícitas nos dados obtidos, imperceptíveis nas análises quantitativas usuais. Ao final dos testes, os resultados fornecem bases para a confirmação da sentença estruturadora ou para a construção de uma nova, com a redefinição das hipóteses inicialmente consideradas.

Caso as hipóteses regionais sejam verificadas, revelam aspectos relativamente estáveis do conceito investigado, dando-lhe legitimidade, além de confirmar a estrutura interna de conceitos e atributos, possibilitando a percepção de componentes empiricamente verificáveis e da forma como se inter-relacionam (SHYE; ELIZUR; HOFFMAN, 1994).

A SSA permite ainda testar se um determinado grupo opera da mesma maneira que outro na avaliação de vitrinas, questão relacionada com o terceiro objetivo formulado na pesquisa. Tal método, segundo Monteiro \& Roazzi (2009), é considerado um grande avanço na SSA e permite a integração de subpopulações no mapa de componentes originais. Logo, em vez de analisar diversas projeções diferentes, produzidas para cada grupo considerado em uma pesquisa, é possível apreciar uma única projeção que retrata, ao mesmo tempo, a estrutura regional e os diferentes subgrupos como variáveis externas.

\section{RESULTADOS PRETENDIDOS}

Pela via proposta, espera-se que os resultados produzidos possam aprimorar, no que for possível, os aportes teórico-conceituais relacionados com o objeto de estudo, a vitrina de rua, ampliando sua abrangência analítica, bem como favorecendo o desenvolvimento de projetos balizados por evidências empíricas que priorizam a cognição das pessoas.

Espera-se, confiante, responder diretamente a todos os objetivos aqui formulados que, em termos gerais, pretende apresentar uma proposta para avaliar a qualidade visual de vitrinas a partir da percepção de especialistas e não especialistas no assunto. Busca-se ainda, mais especificamente, testar a aderência de certas características visuais de vitrinas para a avaliação da sua qualidade visual percebida; verificar a influência dessas características nos aspectos de prazer, excitação e calmaria em vitrinas e, finalmente, analisar o consenso dos resultados entre os dois diferentes grupos abordados.

Os achados poderão confirmar as características da vitrina determinantes para a avaliação da sua qualidade visual percebida, os efeitos da complexidade e da coerência da vitrina na percepção de sua qualidade visual e, finalmente, demonstrar se vitrinistas, comerciantes e consumidores compartilham respostas avaliativas ou estéticas. Será, dessa forma, possível compreender como diferentes configurações de vitrinas podem ser obtidas para diversos fins, ou seja, como criar uma vitrine agradável, estimulante, emocionante, tranquila.

Em última análise, espera-se que os vitrinistas poderão fazer bom uso dos dados empíricos produzidos através dessa pesquisa, no sentido de obter bases científicas seguras para embasar suas decisões projetuais. Nessa linha, a abordagem proposta poderá, ainda, contribuir para a melhoria da qualidade visual percebida de vitrinas.

\section{REFERÊNCIAS}

BERLYNE, D. E. Ends and meanings of experimental aesthetics. Canadian Journal of Psychology, n. 26, p. 303-325, 1972.

BAPTISTA, A.; MARTINS, L.; SOARES, M. Metodologia ergonômica aplicada ao ambiente construído: o usuário no espaço urbano. In: VII CONGRESSO LATINO-AMERICANO DE 


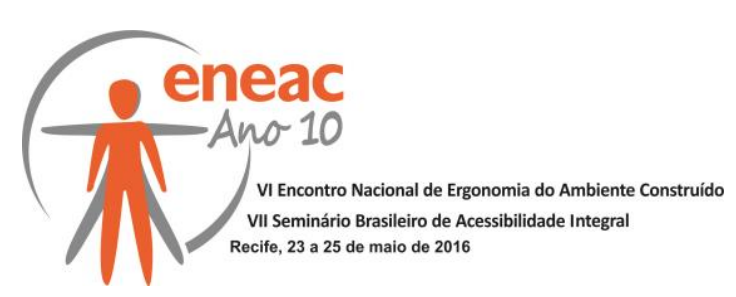

ERGONOMIA, XII CONGRESSO BRASILEIRO DE ERGONOMIA, I SEMINÁRIO BRASILEIRO DE ACESSIBILIDADE INTEGRAL, 2002, Recife. Anais... Recife: UFPE, 2002.

BIGAL, S. Vitrina, do outro lado do visível. São Paulo: Nobel, 2001.

BILSKY, W. Teoria das Facetas: noções básicas. In Estudos de Psicologia v.8, n.3, 2003 p.357-365.

BINS ELY, V. H. Acessibilidade Espacial: Condições necessária para o projeto de ambientes inclusivos. In: MORAES, Anamaria de (Org.). Ergonomia do ambiente construído: ambiente urbano, ambiente público, ambiente laboral. Rio de Janeiro: iUsEr, 2004, p. 17-40.

CANTER, D.; BROWN, J.; GROAT, L. A multiple sorting procedure for studying conceptual systems, In: M. Brenner, J. Brown, D. Canter (Eds). The research interview: uses and approaches. London: Academic Press 79- 114.

COSTA FILHO, L. L. MIDIÁPOLIS: comunicação, persuasão e sedução da paisagem urbana midiática. 2012. 271f. Tese (Doutorado) - Universidade Federal de Pernambuco, Recife, 2012.

. O enfoque da Teoria das Facetas na avaliação de lugares. In: V ENEAC - ENCONTRO NACIONAL DO AMBIENTE CONSTRUÍDO E VI SEMINÁRIO NACIONAL DE ACESSIBILIDADE INTEGRAL, 2014. Rio de Janeiro. Anais... Rio de Janeiro: LEUI | PUC-Rio, 2014.

KAPLAN, S.; KAPLAN, R. Cognition and environment: functioning in an uncertain world. New York: Praeger, 1982.

LOURENÇO, F.; SAM, J. Vitrina: veículo de comunicação e venda. São Paulo: Editora SENAC, 2011. LYNCH, K. A imagem da cidade. São Paulo: Editora Martins Fontes, 1997.

MONTEIRO, C. M. G.; ROAZZI, A. Polemic images: Dwellers' concepts of life in historic areas. In: COHEN, Arie (Ed.). Facet Theory and scaling: in search of structure in behavioral and social sciences. Israel: Rubin R. I. D, 2009.

MONT'ALVÃO, C.; FIGUEIREDO, J. A ergonomia ambiental no processo de composição cromática de locais de trabalho de escritórios. In: MORAES, Anamaria de (Org.). Ergonomia do ambiente construído: ambiente urbano, ambiente público, ambiente laboral. RJ: iUsEr, 2004, p. 109-134.

NASAR, J. The evaluative image of places. In W. Bruce Walson, Kenneth H. Craik, Richard H. Price. (Eds.). Person-environment psychology: New directions and perspectives. New Jersey: Lawrence Erlbaum Associates, Inc., 2000.

The evaluative image of the city. London: SAGE, 1998.

Environments aesthetics: theory, research, and applications. New York: Cambridge University Press, 1988.

OLIVEIRA, A. C. Vitrinas: acidentes estéticos na cotidianidade. São Paulo: EDUC, 1997.

ROAZZI, A.; MONTEIRO, C. M. G.; RULLO, G. Residential satisfaction and place attachment: in cross-cultural investigation. In: A. Cohen (Ed). Facet Theory and scaling: search of structure in behavioral and social sciences. Israel: Rubin R. I. D, 2009.

SHYE, S.; ELIZUR, D.; HOFFMAN, M. Introduction to Facet Theory: Content design and intrinsic data analysis in behavioral research. London: Sage, 1994.

STAMPS, A. E. Perceptual and preferential effects of photomontage simulations of environments. In Perceptual and Motor Skills, № 74, 1992.

VARGAS, Heliana Comin. Espaço terciário: o lugar a arquitetura e o espaço do comércio. São Paulo: Ed. SENAC São Paulo, 2001.

VILLAROUCO, V. Tratando de ambientes ergonomicamente adequados: seriam ergoambientes? In: MONT'ALVÃO, C. e VILLAROUCO, V. (Orgs.). Um novo olhar para o projeto: a ergonomia no ambiente construído. Teresópolis: 2AB, 2011, p. 25-46.

WOHWILL, J. Environmental aesthetics: The environment as a source of affect. In: I. Altmann; J. Wohwill (Eds.), Human behavior and environment, v.1, 37-86, 1976.

WOLF, R. Prefácio. In: DEMESTRESCO, S. Vitrinas e exposições: arte e técnica do Visual Merchandising. 1. ed. São Paulo: Érica, 2014. 